\title{
Um estudo das representações semióticas de função via uma atividade de modelagem matemática
}

Oscar Luiz Teixeira de Rezende oscarltr@gmail.com

0000-0001-5591-8562

Instituto Federal de Educação,

Ciência e Tecnologia do Espírito

Santo, Vitória, Espírito Santo, Brasil

Luciano Lessa Lorenzoni

Illorenzoni@ifes.edu.br

0000-0003-4859-7750

Instituto Federal de Educação,

Ciência e Tecnologia do Espírito

Santo, Vitória, Espírito Santo, Brasil

Maria Alice Veiga Ferreira de

Souza

alicevfs@gmail.com

0000-0003-2038-813X

Instituto Federal de Educação

Ciência e Tecnologia do Espírito

Santo, Vitória, Espírito Santo, Brasil

\section{RESUMO}

Esse estudo teve como objetivo verificar como os alunos lidam com os diferentes registros de representação semiótica do objeto matemático função, por meio de uma atividade de modelagem matemática cujo tema foi a produção de carvão vegetal. A pesquisa realizada é de cunho qualitativo e utilizou como instrumentos de produção de dados os registros escritos dos alunos, os diários de bordo dos pesquisadores e as gravações em áudio. A investigação contou, principalmente, com apoio teórico das ideias de Duval para a fundamentação das representações semióticas. Os resultados indicaram que os participantes apresentaram dificuldades em transitar de um registro de representação semiótica a outro e de efetuar as transformações no interior do mesmo registro, indicando que o conceito de função não foi bem compreendido. Além disso, observamos que, de um modo geral, os alunos envolvidos nessa pesquisa ainda distanciam a matemática do mundo real, dissociam a realização da tarefa e o seu sentido e têm dificuldades para transferir/aplicar conteúdos já estudados para novos contextos.

PALAVRAS-CHAVE: Modelagem matemática. Função. Registro de representação semiótica. 


\section{INTRODUÇÃO}

A Modelagem Matemática, que no texto utilizaremos o termo modelagem, é considerada por professores e pesquisadores em Educação Matemática como uma alternativa pedagógica para o ensino da matemática. A modelagem aborda problemas de outras áreas do conhecimento e da realidade do aluno, aproximando o "mundo real" da sala de aula. Rezende e Lorenzoni (2013) sugerem que a modelagem pode ser uma estratégia metodológica que instigue o aluno a "fazer a matemática" de modo que ele possa compreender e interferir nos fenômenos que o cerca reduzindo a distância entre a matemática que ele pratica, no mundo real, e a apresentada nas salas de aula.

Um dos conteúdos matemáticos propício a ser estudado a partir de atividades de modelagem é o de funções. De acordo com as Orientações Curriculares para o Ensino Médio, o ensino de funções deve contemplar uma exploração qualitativa entre grandezas e deve contemplar diferentes modelos (linear, quadrático, exponencial, ...) abordando problemas de diversas áreas do conhecimento (BRASIL, 2006). Isto é, deve buscar a contextualização e a interdisciplinaridade, que, em síntese, é o que propõe uma atividade de modelagem.

Quando os alunos desenvolvem uma atividade de modelagem para identificar qual o modelo de função que descreve um fenômeno em estudo, várias etapas metodológicas são percorridas: a busca de um problema na realidade, a atribuição de hipóteses simplificadoras, a construção e a resolução do modelo de função e, finalmente, a sua validação. Nessas etapas, principalmente na construção e resolução do modelo, são utilizados símbolos e diferentes representações do objeto matemático função (tabela, gráfico e representação algébrica), que estão diretamente envolvidos nos registros de representação semiótica, foco de nosso interesse.

De modo específico, Maggio, Soares e Nehringn (2010) identificaram que o estudo da função afim, comumente proposta em sala de aula e baseada em livros didáticos, pouco possibilita ao aluno acesso aos diferentes registros de representação semiótica do objeto matemático, justificando, assim, a utilização de novas abordagens metodológicas, como exemplo, a modelagem. Vertuan (2007) reforça que a modelagem é uma alternativa pedagógica que pode propiciar ao aluno acesso a diferentes registros de representação.

Silva e Veronez (2014) afirmam, que no trabalho com modelagem, de maneira geral, há uma diversidade de usos de representações a fim de se obter uma solução para o problema que emergiu de uma situação inicial. A coordenação dessas representações é um dos pressupostos teóricos dos registros de representação semiótica desenvolvido por Raymond Duval que, por sua vez, está relacionada com a aprendizagem matemática. Do mesmo modo, Amouloud (2014) ao falar de registros de representação semiótica, da coordenação e da conversão de registros, coloca em jogo o problema da aprendizagem e disponibiliza ao professor instrumentos que poderão ajudá-lo a tornar mais acessível a compreensão da matemática.

Colombo, Flores e Moretti (2008) trazem uma reflexão sobre a forma de utilização dos estudos de Raymond Duval acerca do papel dos registros de representação semiótica no ensino e na aprendizagem da matemática, a partir da análise de pesquisas realizadas no Brasil no período de 1990 a 2005, apontando 
possibilidades de utilização dessa teoria na organização de propostas curriculares e na formação inicial e continuada de professores que ensinam matemática. Santos e Curi (2011) , Bariccatti e Vertuan (2012), Lucas e Gualandi ( 2015) e Figueroa e Almouloud ( 2015) também partem de um pressuposto de ensino e de aprendizagem pautados na necessidade de atribuir significado ao objeto matemático em estudo por meio de suas diferentes representações.

Mais recentemente, pesquisa desenvolvida por Pontes, Finck e Nunes (2017) apresentou um estudo do estado da arte da teoria das representações semióticas na educação matemática, num recorte temporal de 2010 a 2015. Os autores concluíram que, dos 65 trabalhos pesquisados, 4 deles tratam de procedimentos metodológicos envolvendo a modelagem e que são mais evidentes nos tarbalhos mapeados as transformações de tratamento e conversão como aspectos da teoria de Raymond Duval.

Entendemos que, na modelagem, as representações semióticas dos objetos matemáticos mobilizados durante a realização da atividade constituem um elemento importante da aprendizagem. Neste contexto, investigamos como os alunos lidam com os registros de representação semiótica do objeto matemático função, utilizando como alternativa pedagógica uma atividade de modelagem (ajuste de curvas) para discutir as possíveis soluções de problemas próximos da realidade. Ou seja, analisamos como os alunos articulam as diferentes representações do objeto matemático função a partir das conversões e tratamentos realizados de acordo com a teoria de Duval.

\section{ASPECTOS RELEVANTES DA TEORIA DOS REGISTROS DE REPRESENTAÇÃO SEMIÓTICA}

A Teoria dos Registros de Representação Semiótica foi desenvolvida por Raymond Duval. Duval (2009) defende que um objeto matemático pode ser representado por meio de registros de representações semióticas, que são produções constituídas pelo emprego de signos (gráficos, tabelas, fórmulas, escrita, ...) pertencentes a um sistema semiótico, os quais têm suas dificuldades próprias de significado e funcionamento. Esses registros, em que representamos um objeto matemático, constituem-se em um espaço de comunicação que possibilita exteriorizar as representações mentais, tornando-as acessíveis a outras pessoas, promovendo a organização de informações do objeto representado.

Duval (2013) salienta que o acesso aos objetos matemáticos, por não serem perceptíveis diretamente, passa necessariamente pela representação semiótica e que a evolução dos conhecimentos matemáticos conduziu ao desenvolvimento de diferentes registros de representação que, por vezes, estão associados a um mesmo objeto matemático. Por exemplo, para o objeto função, Amouloud (2014) afirma que ele pode ser representado por quatro registros de representação semiótica: tabelas, fórmulas algébricas, gráficos e símbolos.

Cada um dos registros de representação semiótica proporciona visões e compreensões distintas, apresentando um conteúdo próprio que pode caracterizar apenas parte do objeto. Diante da limitação de se representar o todo (as diferentes características e propriedades de um objeto matemático), surge a mesmo objeto (MORETTI, 2002). Além disso, Moretti (2002, p. 27) explica que "de 
um ponto de vista cognitivo, uma representação é parcial em relação aquilo que ela quer representar e que de um registro a outro não são os mesmos conteúdos de uma situação que são representados".

O sujeito vai se apropriando do objeto ao identificar em cada um dos registros de representações os elementos e propriedades que o caracteriza, ao estabelecer relações e transitar a partir de transformações de um registro para outro. Existem, segundo Duval (2009), dois tipos de transformações: um interno, os tratamentos, e outro externo, as conversões.

Os "tratamentos" são transformações de representações dentro de um mesmo registro. São estritamente internos ao registro, estando especificamente relacionados à forma e não ao conteúdo do objeto matemático (DAMM, 2002). Exemplos de tratamentos seriam a realização de um cálculo numérico ou algébrico. Em geral, os tratamentos são específicos de cada registro.

Já as "conversões", segundo Duval (2009), são transformações de representação que consistem em mudança de registro conservando os mesmos objetos matemáticos denotados. Nessa transformação ocorre a mudança de um registro de representação para outro registro, alterando-se a forma de apresentar o conteúdo, mas preservando a referência ao mesmo objeto. Um exemplo de conversão seria reconhecer uma função num registro de representação algébrica e em seu registro de representação gráfica.

Duval (2009) ressalta que a atividade de conversão dos vários registros de representações acerca do objeto matemático conduz aos mecanismos subjacentes à compreensão, possibilitando a construção do conhecimento. Reforça, ainda, que uma condição necessária ao processo de aprendizagem é a possibilidade de coordenação/mudança dos registros. Para Duval (2013, p. 14) "a originalidade da atividade matemática está na mobilização simultânea de ao menos dois registros de representação ao mesmo tempo, ou na possibilidade de trocar a todo momento de registro de representação".

Adicionalmente, D'amore (2005) reforça que a construção dos conceitos engloba três ações fundamentais, quais sejam: representar os conceitos, tratar as representações obtidas no registro estabelecido e converter as representações de um registro para outro.

\section{PROCEDIMENTOS METODOLÓGICOS, RESULTADOS E ANÁLISES}

Esse estudo de cunho qualitativo utilizou como instrumentos de produção de dados os registros escritos dos alunos, os diários de bordo dos pesquisadores e as gravações em áudio. Foi desenvolvido tendo como sujeitos 33 estudantes de uma turma do $2 \circ$ ano do ensino médio integrado ao curso técnico, de uma instituição capixaba, em duas aulas geminadas totalizando 100 minutos. Ressalta-se que esses alunos já haviam estudado no 1ㅇano o objeto matemático função, de modo que a atividade foi elaborada para que pudessem aplicar o conceito de função, já estudado, e lidar com os diferentes registros de representação semiótica do objeto matemático função.

Os autores deste artigo apresentaram aos alunos uma atividade de modelagem, caracterizada, segundo Barbosa (2004), como do caso I, quando o professor propõe a atividade sugerindo o tema e apresentando os dados extraídos 
de uma realidade. Cabe ao aluno a construção, a resolução e a validação do modelo. Prado, Silva e Santana (2013) apresentam, ainda, uma categorização para as atividades desenvolvidas nesse caso, a saber: tarefa aberta, tarefa semifechada e tarefa fechada. No nosso caso, consideramo-la como semifechada por entendermos que, apesar de em algumas questões ser indicado especificamente o objeto matemático função a ser utilizado na resolução, existem diferentes tipos de função que poderiam ser utilizados, e não há a indicação explícita de quais dados devem ser manipulados, possibilitando certa autonomia aos estudantes.

Inicialmente, foi exibido um vídeo de 10 minutos de duração visando situar os estudantes sobre o problema a ser estudado (o processo de produção do carvão vegetal) abordando os seguintes aspectos: o processo de corte da madeira, o seu aquecimento para formar a massa de carvão e o resfriamento dessa massa, a sua utilização na indústria do aço, muito comum aos alunos do Espírito Santo por se tratar de uma atividade industrial presente em nossa região e próxima do curso que faziam, e os problemas ambientais e sociais causados na sua produção.

Após assistirem ao vídeo, os estudantes foram divididos em 11 grupos de 3 alunos. Cada grupo recebeu um material impresso constituído de um esquema do ciclo de modelagem, um texto resumido sobre a atividade da produção de carvão, e os dados de tempo e de temperatura do resfriamento da massa de carvão (Tabela 1), que são uma adaptação dos dados obtidos experimentalmente por Reis (2009).

Tabela 1: Dados de resfriamento de uma massa de carvão vegetal

\begin{tabular}{|c|c|c|c|c|c|c|c|c|c|c|}
\hline $\begin{array}{c}\text { Tempo } \\
\text { (h) }\end{array}$ & 0 & 3 & 6 & 9 & 12 & 15 & 18 & 21 & 24 & 27 \\
\hline $\begin{array}{c}\text { Temperatura } \\
\text { (으) }\end{array}$ & 485,7 & 394,7 & 331,6 & 301,6 & 206,3 & 150,6 & 114,5 & 75,1 & 60,8 & 50,9 \\
\hline
\end{tabular}

(Fonte: Reis (2009, adaptado))

No material impresso distribuído, os alunos foram solicitados a responder às seguintes questões: 1) plotar em um gráfico cartesiano os dados de resfriamento da massa de carvão, identificando as variáveis dependente e independente; 2) sugerir uma fórmula algébrica de função que melhor se aproximasse dos dados; 3 ) determinar, com os seus conhecimentos prévios sobre funções, os parâmetros do modelo de função sugerido; 4) estimar o tempo que a massa de carvão atingiu a temperatura ambiente, estipulada em $25^{\circ} \mathrm{C} \mathrm{e} ; 5$ ) apresentar uma estratégia para validar e avaliar a qualidade do modelo sugerido. Essa sequência de tarefas foi elaborada com o intuito de produzir dados para a análise da compreensão do objeto matemático função pelo aluno por meio da mobilização de diferentes registros de representação semiótica (tabular, gráfico e algébrico).

Para responder à tarefa 1), o aluno deveria realizar uma conversão do registro tabular para o registro gráfico, assim como em 2), uma conversão do registro gráfico para o algébrico. Já em 3) e 4), deveria realizar transformações internas no registro algébrico, ou seja, tratamentos. Ressaltamos que cada grupo poderia escolher entre os diversos tipos de função (que já haviam estudado no ano anterior), tais como linear, quadrática, exponencial ou logarítmica, de acordo com o que considerasse mais adequado para modelar o fenômeno proposto. 0 mais relevante para a investigação, independentemente do tipo de função escolhido, 
seria identificar a capacidade do aluno de mobilizar diferentes registros para a função escolhida e, com isso, de acordo com Duval (2009), verificarmos a apreensão desse conceito em particular.

O ciclo apresentado aos alunos no material impresso foi uma tradução livre do Ciclo da Modelagem de Blum e Leib (2006) apud Perrenet e Zwaneveld ( 2012, p.4), Figura 1, explorando e evidenciando cada uma das suas sete etapas.

Figura 1: Adaptação do ciclo de modelagem de Blum e Leib (2006)

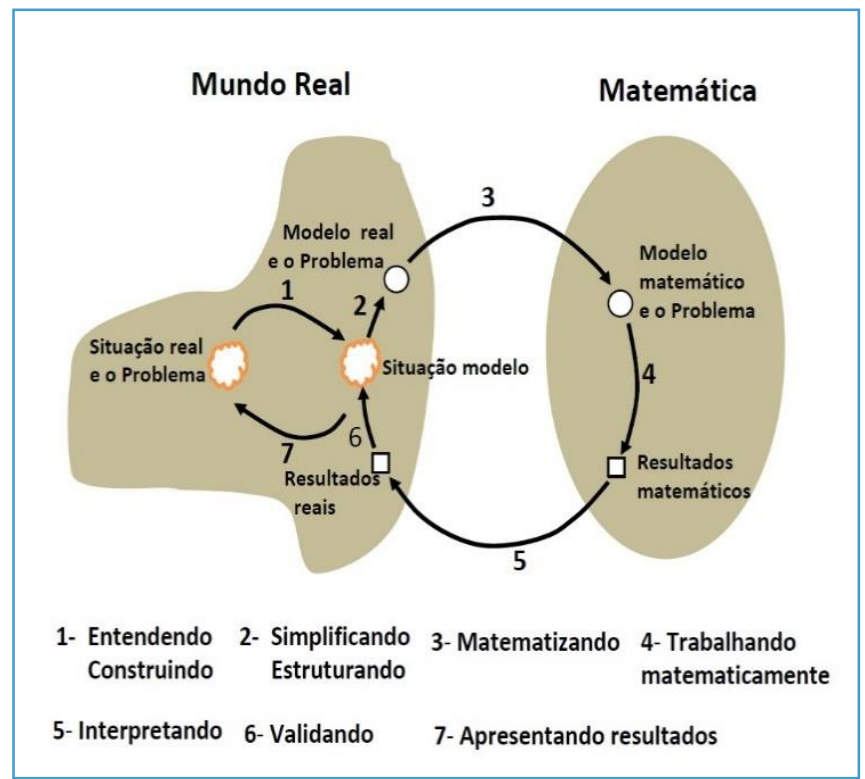

(Fonte: Perrenet e Zwaneveld (2012))

Na nossa pesquisa, o esquema do ciclo de modelagem cumpriu com dois objetivos: o primeiro, apresentar para o aluno, em termos metodológicos, no que se constitui uma atividade de modelagem. $O$ segundo, foi o de identificarmos as três categorias e doze subcategorias de respostas dos alunos para as questões/etapas propostas na atividade, a fim de guiar as discussões e análises sobre as representações de uma função adotada e suas transformações.

As categorias e subcategorias utilizadas na análise foram construídas centradas nas seguintes etapas do ciclo da modelagem: a etapa 3- matematizando, que consistiu na plotagem em um gráfico cartesiano dos dados tabelados e na sugestão de uma fórmula algébrica para a função que melhor se aproxima dos dados tabelados; a etapa 4- trabalhando matematicamente, na busca dos parâmetros do modelo sugerido e a determinação do tempo que a massa de carvão atingiu a temperatura ambiente e; a etapa 6-validando, em que foi solicitada aos alunos uma estratégia para validar e avaliar a qualidade da expressão algébrica sugerida.

A opção por apenas essas etapas como categorias de análise se justificam pelo interesse em verificar, especificamente, os registros de representação propostos e as transformações (tratamento e conversão) realizadas pelos alunos nessas etapas. Pudemos observar se os alunos construíram o gráfico, propuseram uma expressão algébrica para o problema apresentado, conseguiram estimar o tempo de resfriamento para que a massa de carvão alcançasse a temperatura ambiente e de que forma chegaram a esse valor, e que estratégia foi adotada para avaliar/validar a qualidade do modelo proposto. Na Tabela 2 apresentam-se as 
categorias e subcategorias adotadas e as respectivas frequências das respostas dos grupos.

Tabela 2: Categorias e subcategorias adotadas e frequências das respostas dos grupos

\begin{tabular}{|c|c|c|c|}
\hline ETAPAS DO CICLO & CATEGORIAS & SUBCATEGORIAS & FREQUÊNCIA \\
\hline \multirow{6}{*}{ Matematizando } & \multirow{2}{*}{ Gráfico } & Sim & 11 \\
\hline & & Não & 0 \\
\hline & \multirow{4}{*}{$\begin{array}{l}\text { Expressão } \\
\text { Algébrica }\end{array}$} & Linear & 1 \\
\hline & & Exponencial & 7 \\
\hline & & Quadrática & 2 \\
\hline & & Logarítmica & 1 \\
\hline \multirow{3}{*}{$\begin{array}{l}\text { Trabalhando } \\
\text { matematicamente }\end{array}$} & \multirow{3}{*}{$\begin{array}{c}\text { Tempo de } \\
\text { Resfriamento }\end{array}$} & Usou o modelo & 0 \\
\hline & & Apresentou uma estratégia & 7 \\
\hline & & Não apresentou uma estratégia & 4 \\
\hline \multirow{3}{*}{ Validando } & \multirow{3}{*}{$\begin{array}{l}\text { Qualidade do } \\
\text { Modelo }\end{array}$} & Aspectos subjetivos & 3 \\
\hline & & Aspectos analíticos & 3 \\
\hline & & Não apresentou uma estratégia & 5 \\
\hline
\end{tabular}

(Fonte: Arquivo dos autores)

Esclarecemos que na subcategoria, "Aspectos subjetivos", foram observadas as respostas em que os alunos se basearam em contextos que não estavam explícitos na atividade, por exemplo, usar um termopar (sensor de temperatura) ou refazer o experimento; e "Aspectos analíticos", em que foram consideradas respostas que os alunos, de alguma forma, utilizaram uma estratégia matemática a partir do modelo para responder à questão relativa a validação do modelo proposto.

Para verificar os objetivos do trabalho, conduzimos a nossa análise a partir dos protocolos escritos e orais dos alunos, buscando compreender como eles lidam com os registros de representação semiótica de função. As análises emergiram das frequências das respostas escritas das tarefas propostas; dos discursos registrados nos diários de bordo; dos registros de representações do objeto matemático função e das transformações dessas representações (tratamento e conversão) extraídas das respostas dos alunos no material impresso.

A etapa 3 (matematizando) representa a transposição do "mundo real" para o "mundo da matemática" por meio da conversão dos registros de representações tabela-gráfico-fórmula algébrica. Na teoria das representações semióticas Duval (2012) define essa transposição como transformações externas de registros. De acordo com a Tabela 2 deduzimos que, para a conversão do registro de representação de uma tabela em um gráfico, os 11 grupos conheciam uma regra de codificação para plotar os pontos da tabela em um plano cartesiano. Segundo Duval (2013) temos o que podemos chamar de uma conversão congruente, o que favorece a compreensão do aluno. No entanto, isso não foi suficiente para que 
operassem a conversão do registro de representação de partida (Tabela) no de chegada (Gráfico), pois todos os grupos procuraram ligar esses pontos, em geral, por meio de segmentos de reta, como fez um dos grupos (Figura 2), para, então, sugerir que tipo de função estaria associada a esse gráfico.

Figura 2: Gráfico plotado por um dos grupos de estudantes

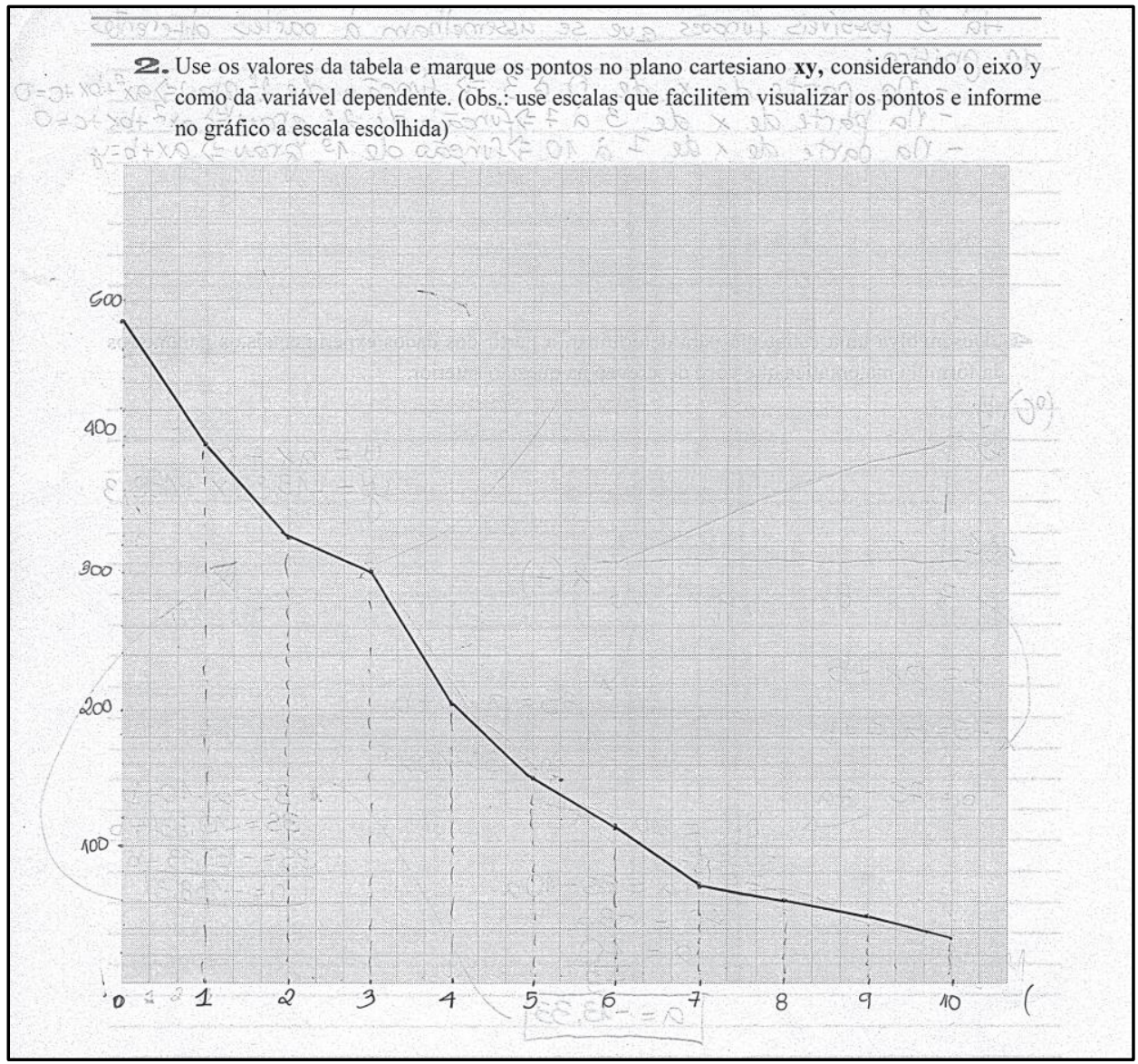

(Fonte: Arquivo dos autores)

Os alunos não se atentaram para o fato dos dados da Tabela 1 representarem o fenômeno de resfriamento da massa de carvão, e que a função que procuravam não era a que passava por todos os pontos, mas aquela que melhor se aproximasse dos pontos. Observamos que eles tinham a expectativa de que os dados propostos se apresentassem "bem-comportados" e se encaixassem em um único e definitivo padrão, pois se referenciavam aos mesmos como "caóticos irregulares" e "achei que a função tinha que ser regular". Essa visão dos alunos é interpretada por Skovsmose (2011) como uma construção, ao longo do tempo, da matemática como pura, um sistema perfeito, infalível, estável e inquestionável, mesmo vivendo e interagindo em um mundo com incertezas, o "mundo real".

Duval (2012) afirma que o caminho das aprendizagens de base matemática não pode ser somente a automatização de certos tratamentos, como fizeram os alunos ao ligarem os pontos por segmentos de reta para traçar o gráfico, mas deve ser a coordenação de diferentes registros de representação, o que não ficou evidente na análise, uma vez que nenhum grupo conseguiu traçar o gráfico corretamente. Ao ligarem os pontos apenas por segmentos de reta (e por que não por uma curva suave?) é um sinal de que os alunos não se atentaram para o 
comportamento do fenômeno que estavam modelando o que pode indicar uma dissociação da realização da tarefa e o seu sentido.

$\mathrm{Na}$ conversão do registro gráfico para o registro fórmula algébrica, todos os grupos sugeriram uma expressão (linear, exponencial, quadrática e logarítmica), conforme mostram os dados na Tabela 2. Temos que 7 dos 11 grupos identificaram o modelo exponencial, mas não estabeleceram uma estratégia que permitisse encontrar os parâmetros do modelo e a sua consequente fórmula de representação algébrica, como pode ser observado nas respostas de um dos grupos (Figura 3).

Figura 3: Resposta de um dos grupos para a sugestão de modelo de função que explicasse o fenômeno e a estratégia para o cálculo dos parâmetros do modelo.

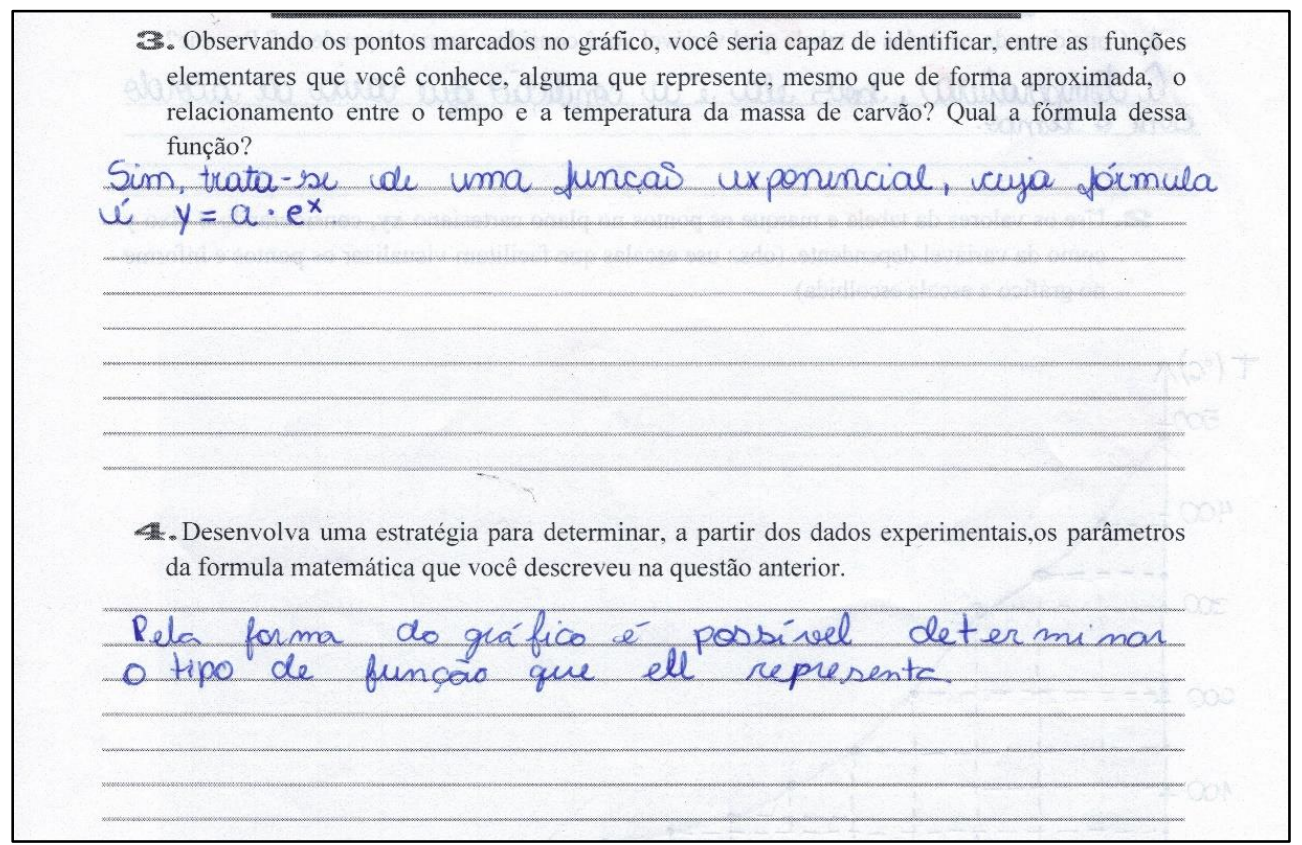

(Fonte: Arquivo dos autores)

Mesmo observando que a maioria dos grupos tenha identificado o modelo exponencial para representação do registro algébrico, eles não conseguiram operar uma mudança de representação nesse registro que permitisse encontrar os parâmetros do modelo, ou seja, não conseguiram fazer o tratamento nesse registro. Isso indica uma dificuldade na conversão do registro gráfico para o registro algébrico. Duval (2012) afirma que a ausência de coordenação entre registros não impede toda a compreensão do objeto, mas essa compreensão não favorece em nada a aprendizagem posterior, pois torna os conhecimentos adquiridos pouco ou não utilizáveis em outras situações, como parece ter acontecido com esses alunos, pois funções é assunto já estudado no currículo do 10 ano dessa instituição.

$\mathrm{Na}$ etapa 4 do ciclo de modelagem (trabalhando matematicamente), apesar de todos os grupos terem apresentado uma função para representar o fenômeno, nenhum dos 11 grupos sugeriu um tempo de resfriamento a partir do modelo de função proposto por eles. É importante ressaltar que mesmo não utilizando o modelo de função sugerido, 7 grupos apresentaram uma estratégia para calcular o tempo de resfriamento, como fez o grupo cujo registro gráfico foi apresentado na Figura 2. O grupo considerou que no intervalo de tempo entre 21 horas e 30 
horas a queda de temperatura segue um modelo linear e estimaram o tempo que a massa de carvão atingiu a temperatura ambiente utilizando esse modelo, conforme Figura 4.

Figura 3 Estratégia utilizada por um dos grupos para determinar o tempo que a massa de carvão atingiu a temperatura ambiente.

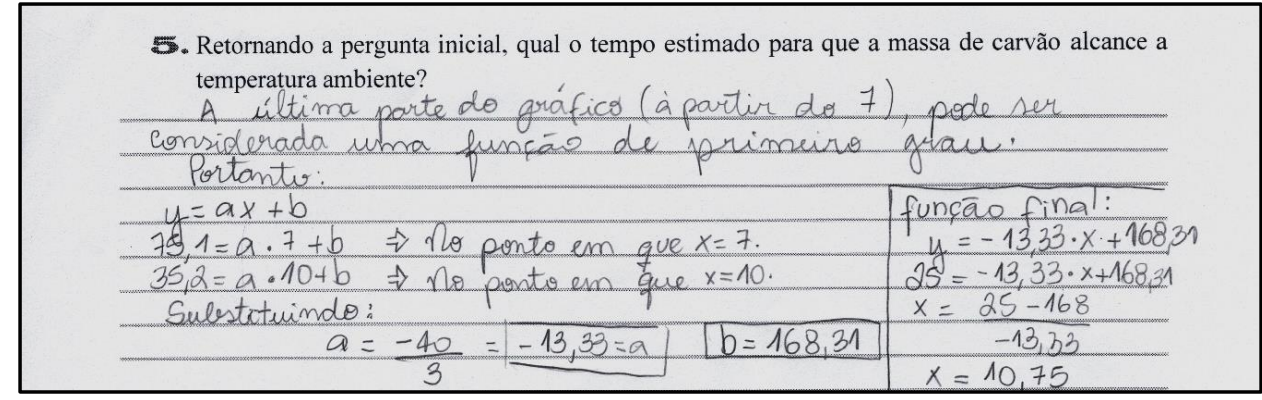

(Fonte: Arquivo dos autores)

Mesmo que alguns grupos tenham desenvolvido uma estratégia para encontrar o tempo de resfriamento da massa de carvão, a operação de tratamento não foi identificada, pois não a fizeram a partir do registro algébrico, ou seja, não utilizaram a expressão matemática que haviam sugerido para descrever o fenômeno.

No geral, os grupos não articularam as variáveis cognitivas específicas do funcionamento de cada um dos registros. Eles criaram variáveis que permitiram um resultado, mas que não são reutilizáveis em outras situações problemas. Duval (2013) afirma que, ao passar de um registro a outro, são essas variáveis (específicas de cada registro) que permitem determinar quais unidades de significado pertinentes devem ser levadas em consideração em cada um dos registros.

Na etapa 6 do ciclo da modelagem (validando), quando foram indagados sobre a qualidade/confiabilidade do modelo obtido, 5 dos 11 grupos não indicaram qualquer estratégia de validação, três apresentaram estratégias analíticas e outros três subjetivas (antes explicadas).

Alguns grupos mostravam-se preocupados em obter a mesma resposta encontrada pelos grupos vizinhos, como constatamos a partir de expressões "bateu com o deles, mas o deles está com uma escala diferente". Entre as estratégias propostas que classificamos como subjetivas para validar o modelo, destacamos: "com um sensor térmico, pode-se analisar a temperatura atingida e comparar com a temperatura ambiente" e "fazer mais experimentos de queima de carvão para fazer a comprovação da fórmula encontrada". E entre os que validaram de forma analítica, consideraram que "o resultado não foi efetivo" mesmo obtendo valores muito próximos entre si.

Observamos com essas respostas o quanto o conteúdo função que ensinamos na sala de aula ainda está desconectado da realidade. Eles não perceberam que, como os dados trabalhados foram obtidos experimentalmente, o modelo matemático que procuravam, não necessariamente, precisava passar por todos os pontos, e que, entre as funções que já haviam estudado, a exponencial, por suas características tais como o decrescimento e um valor assintótico quando o tempo cresce muito, era a mais adequada para representar a situação proposta. 
Nosso diagnóstico se apoia no que afirmam Colombo, Flores e Moretti (2008) ao concluírem que a grande maioria das pesquisas em Educação Matemática no Brasil no período de 1990 a 2005 indicaram que, tanto os livros didáticos, quanto o trabalho do professor carecem da perspectiva de uma utilização efetiva da noção teórica dos registros de representação semiótica.

\section{CONCLUSÕES}

Os resultados permitem concluir que os alunos manifestaram dificuldades de mobilizar mais de um registro de representação semiótica para representar o objeto matemático função e de efetuar as transformações no interior do mesmo registro, indicando que o conceito de função, nesse caso específico, não foi bem compreendido.

Observamos ainda que os alunos, de um modo geral, envolvidos nessa pesquisa ainda distanciam a matemática do mundo real, suprimindo conexões fundamentais, dissociando a realização da tarefa e o seu sentido e têm dificuldades para transferir/aplicar conteúdos já estudados para novos contextos, uma vez que o objeto matemático função já havia sido estudado no ano anterior.

O nosso entendimento é que a atividade de modelagem, associada aos registros de representação semiótica, pode contribuir com o processo de ensino e aprendizagem de funções, especialmente nas seguintes perspectivas: propiciar o desenvolvimento de capacidades que possibilitem o aluno intervir na realidade de onde surgiu o problema; construir um olhar mais crítico da matemática, a partir da ação e da reflexão; e construção de conceitos matemáticos, pois se caracteriza em um ambiente favorável para as mudanças de representação semiótica do objeto matemático em estudo e que possibilita a aplicação do conceito em diferentes contextos, facilitando a sua mobilização em situações futuras. 


\title{
A study of semiotic representations of function via mathematical modeling activity
}

\begin{abstract}
This study aimed to verify how students deal with different registers of semiotic representation of the mathematical object function through a modeling activity that had the production of charcoal as its theme. The results indicated that most of the students involved in this qualitative research still keep mathematics far from the real world, suppressing fundamental connections, dissociate the realization of the task and its meaning and have difficulties to transfer/apply content already studied to new contexts. Furthermore, the participants had difficulties in moving from one semiotic representation register to another and making changes within the same register, indicating that the concept of function was not well understood. The investigation was mainly supported by the theory of Duval the semiotic representations.
\end{abstract}

KEYWORDS: Mathematical modeling. Function. Register of semiotic representation. 


\section{AGRADECIMENTOS}

Os autores agradecem ao CNPq e a Vale pelo financiamento do projeto de pesquisa e a concessão de bolsas ao professor e aos alunos de iniciação científica participantes.

\section{REFERÊNCIAS}

AMOULOUD, S. A. Fundamentos da didática da matemática. Curitiba PR: Editora UFPR, 2014.

BARBOSA, J.C. Modelagem Matemática: O que é? Por que? Como? Veritati, v. 2 n. 4, p. 73-80, 2004.

BARICCATTI, K. H.; VERTUAN, R. E. Os diferentes sentidos das representações dos objetos matemáticos e as atividades de tratamento e conversão entre registros. Revista Eletronica de Educação Matemática, p. v. 07, n. 1, páginas 32-47, 2012.

BRASIL. Orientações Curriculares Para o Ensino Médio. Brasilia: Ministerio da Educação, Secrertaria de Educação Básica, 2006.

COLOMBO, J. A. A.; FLORES, C. R.; MORETTI, M. T. Registros de representação semiótica nas pesquisas brasileiras em Educação Matemática: pontuando tendências. ZETETIKÉ - FE - Unicamp, v. 16, n. 29, p. 41-72, 2008.

D'AMORE, B. Epistemologia e Didática da Matemática. São Paulo-SP: Escrituras, 2005.

DAMM, R. F. Registros de Representação. In: MACHADO, Silvia Dias Alcantara (Org.). Educação Matemática: uma (nova)introdução. São Paulo- SP: EDUC, 2002. p. 135-153.

DUVAL, R. Registros de representação semiótica e funcionamento cognitivo do pensamento. Revista Eletrônica de Educação Matemática, v.7, N.2, p. 226-297, 2012.

DUVAL, R. Semiósis e Pensamento Humano. São Paulo-SP: Editoria Livraria da Fisica, 2009.

DUVAL, R. Registros de Representações Semióticas e Funcionamento Cognitivo da Compreensão em Matemática. In: MACHADO, Sivia Dias Alcântar (Org.). 
FIGUEROA, T. P.; ALMOULOUD, S. A. Proposta de uma Metodologia de Ensino de Espaço Vetorial. Revista Brasileira de Ensino de Ciência e Tecnologia, v. 8, n. 4, set-dez, 2015.

LUCAS, T. M.; GUALANDI, J. H. As Diferenças Formas de Registro de Funções Exponenciais. [S.I.]: Anais do VI SIPEM - Seminário Internacional de Pesquisa em Educação Matemática, Pirenópolis, Goiás, 2015.

MAGGIO, D. P.; SOARES, M. A. S.; NEHRING, C. M. Registros de representação semiótica da função afim: análise de livros didáticos de matemática no ensino médio. Revista Eletrônica de Educação Matemática, v. 5, n.1, p. 38-47, 2010.

MORETTI, M. T. O papel dos registros de representação na aprendizagem de matemática. Contrapontos, v. 6, set/dez, p. 23-37, 2002.

PERRENET, J. ; ZWANEVELD, B. The Many Faces of the Mathematical Modeling Cycle. Journal of Mathematical Modelling and application, v. 1, N.6, p. 3-21, 2012.

PONTES, H. M. DE SOUZA; FINCK, CELIA BRANDT; NUNES, A. L. R. O estado da aarte da teoria de registro de representação seemiótica na educação matemática. Educação Matematica Pesquisa, p. 297-325, 2017.

PRADO, A.S.; SILVA, L. A.; SANTANA, T. S. UMA ANÁLISE BERNSTEINIANA DE TAREFAS DE MODELAGEM MATEMÁTICA NO CASO 1. In: VIII CONFERÊNCIA SOBRE MODELAGEM NA EDUCAÇÃO MATEMÁTICA- CNMEM, 2013, Santa Maria - RS. Anais... Santa Maria - RS: [s.n.], 2013. p. 1-12.

REIS, H. O. Resfriamento de fornos de carbonização por meio de injeção vapor d'água. 2009. Dissertação(Mestrado em Engenharia Agrícola) 148 f. Universidade Federal de Viçosa, Viçosa- MG, 2009.

REZENDE, O. L. T.; LORENZONI, L. L. A Modelagem Matemática em Cursos de Graduação Utilizando Software Estatístico. XI ENEM. Curitiba PR: Curitiba-PR, Anais... Curitiba-PR, 2013. .

SANTOS, C. A. B.; CURI, E. Os Registros de Representação Semiótica como Ferramenta Didática no Ensino da Disciplina de Física. Revista Eletrônica de Educação Matemática, v. 06, n. 1, páginas 1-14, 2011. 
104.

SKOVSMOSE, O. Educação matemática crítica: a questão da democracia. 6. ed. São Paulo- SP: Papirus, 2011.

VERTUAN, R. E. Um olhar sobre a Modelagem Matemática à luz da Teoria dos Registros de Representação Semiótica. 2007. Dissertação (Mestrado em Ensino de Ciências e Educação Matemática) - Universidade Estadual de Londrina, Londrina - PR, 2007.

\section{Recebido: 2017-08-22}

Aprovado: 2018-08-22

DOI: $10.3895 /$ rbect.v11n3.6968

Como citar: REZENDE, O. L. T.; LORENZONI, L. L.; SOUZA, M. A. V. F. Um estudo das representações semióticas de função via uma atividade de modelagem matemática. Revista Brasileira de Ensino de Ciência e Tecnologia, v. 11, n. 3, 2018. Disponível em: <https://periodicos.utfpr.edu.br/rbect/article/view/6968>. Acesso em: xxx. Correspondência: Luciano Lessa Lorenzoni - Illorenzoni@ifes.edu.br Direito autoral: Este artigo está licenciado sob os termos da Licença Creative Commons-Atribuição 4.0 Internacional.

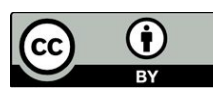

